\title{
CDE Regimen
}

National Cancer Institute

\section{Source}

National Cancer Institute. CDE Regimen. NCI Thesaurus. Code C63469.

An regimen consisting of cyclophosphamide, doxorubicin and etoposide administered as a continuous infusion, used for the treatment of aggressive forms and AIDS-related nonHodgkin lymphoma. 